\title{
Clinical and Blood Biochemical Changes during Induction of Endotoxaemia in Heifers
}

Injection of endotoxins shows clinical and blood biochemical changes similar to what is seen in cases of sepsis with Gram-negative bacteria. In order to evaluate the significance of endotoxaemia in ruminant diseases such as ruminal acidosis/overfeeding and paresis puerperalis it is important to have well-defined parameters of the expected changes. The purpose of this study is to describe the changes in heifers after exposure to endotoxins and is to be used as references in complex disease syndromes in ruminants. Four healthy heifers, 3 Swedish Red and White and 1 Swedish Holstein, aged around $11 / 2$ years, weighing 418 to $454 \mathrm{~kg}$, were used. An endotoxin from Salmonella typhimurium was administered intravenously in a dose of $1 \mu \mathrm{g} / \mathrm{kg}$ to the heifers. The endotoxin batch and preparation was the same as described before (Fredriksson 1984). Blood was sampled every $2 \mathrm{~h}$ for $26 \mathrm{~h}$ before injection and at 20,40,60,80,100,120, 140, $160,180,240,300,360 \mathrm{~min}$ and then every $2 \mathrm{~h}$ during $72 \mathrm{~h}$. The collections were done in plain Vacutainer tubes or tubes containing heparin or EDTA. Plasma was analysed for the content of 15-ketodihydro-PGF $2 a$ (PG) (Granström \& Kindahl 1982). Whole blood was analysed for total white blood cell number (WBC) and differential count simplified by dividing the cells in polymorphonuclear (PMN) and mononuclear (MN). Se-

This study is supported by grants from the Swedish Council for Forestry and Agricultural Research. rum was analysed for calcium $(\mathrm{Ca})$, zinc $(\mathrm{Zn})$, iron $(\mathrm{Fe})$, bile acids (BA), glutamate dehydrogenase (GLDH), sodium $(\mathrm{Na})$ and potassium (K) according to standard methods validated at the Clinical Chemistry Laboratory, Faculty of Veterinary Medicine, Swedish University of Agricultural Sciences, Uppsala, Sweden. Rectal body temperature (BT) was measured every $2 \mathrm{~h}$ throughout the period of study and every hour on the day of injection. Ruminal contractions (RC) were followed every $2 \mathrm{~h}$ during daytime throughout the experimental period. The changes in all parameters throughout the experimental period were evaluated by a one-way factorial analysis of variance (Statgraphics Version 4.0, STSC, Inc., Rockville, MD, USA) and a confidence interval test was used to compare means. The parameters, except for ruminal contractions, as described in Fig. 1, are expressed as means with significant decreases or increases labelled with an asterisk.

All animals showed clinical signs of endotoxaemia: depression, anorexia, increased salivation, respiratory distress, muscle shivering, ruminal stasis - no clear contraction sounds could be recorded and ruminal contractions significantly decreased at $4 \mathrm{~h}$ and increased to normal frequency about $28 \mathrm{~h}$ after injection. Rectal body temperature showed a slight initial decrease and then a pronounced increase after injection and the increase was significant at $18 \mathrm{~h}(40.3 \pm$ $0.4^{\circ} \mathrm{C}$ ) post-injection. A rapid significant increase of the plasma levels of 15-ketodihydro-PGF $2 \alpha$ occurred 1-3 h post-in- 

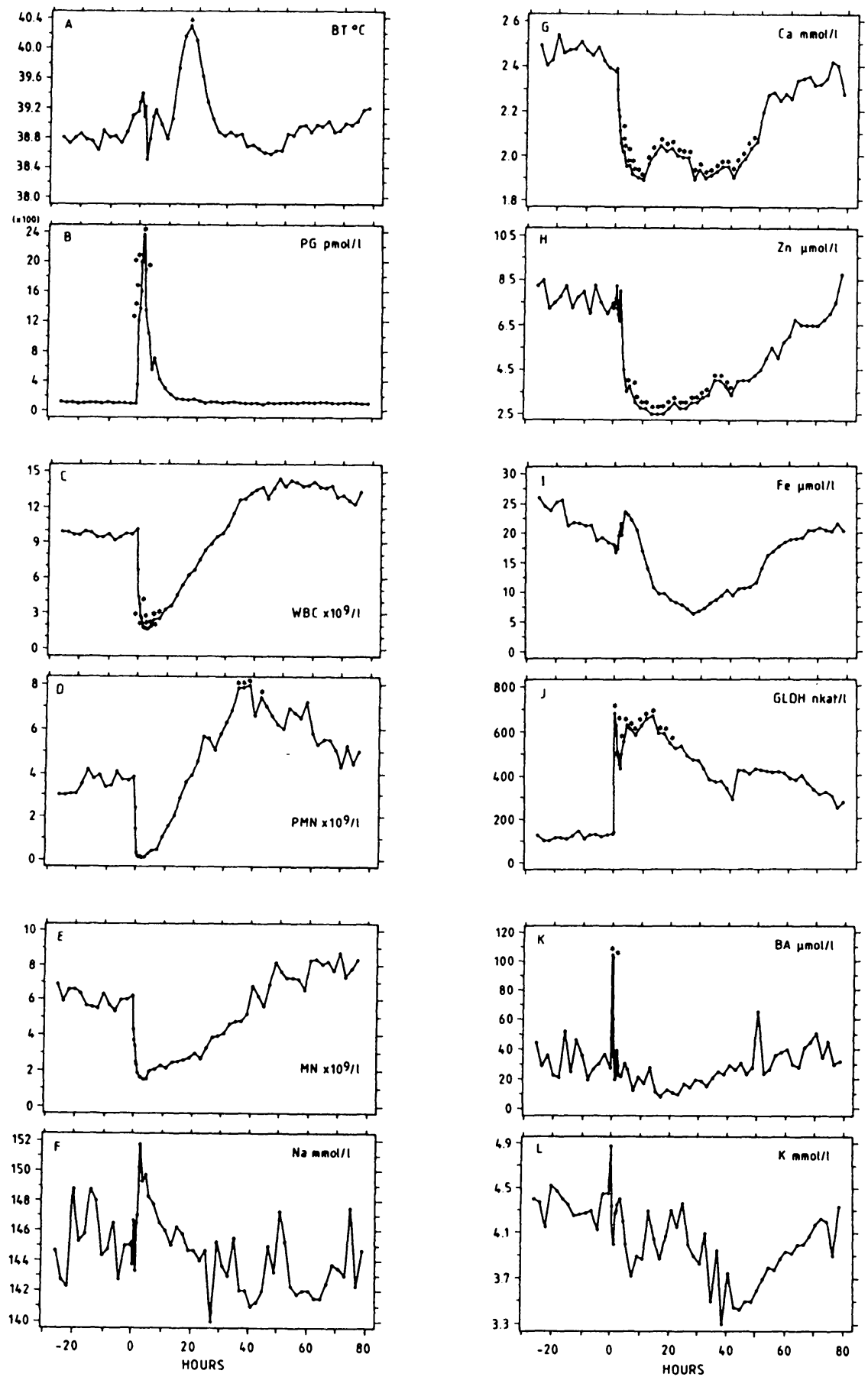
Table 1. A summary of the pathophysiological changes seen in endotoxaemia arbitrarily divided in $\mathbf{4}$ different time periods.

\begin{tabular}{lcccc}
\hline Time (h) & $0-2$ & $2-4$ & $4-6$ & 24 \\
\hline Body Temperature & 0 & $(-)$ & 0 & $(+)$ \\
Ruminal Contraction & - & - & - & 0 \\
Prostaglandin F2a & + & + & $(+)$ & 0 \\
Calcium & $(-)$ & - & - & - \\
Zinc & $(-)$ & $(-)$ & - & - \\
Iron & $(+)$ & $(-)$ & $(-)$ & $(-)$ \\
Glutamate Dehydrogenase & + & + & + & $(+)$ \\
Bile Acids & + & $(-)$ & $(-)$ & $(-)$ \\
Sodium & $(+)$ & 0 & 0 & $(-)$ \\
Potassium & $(+)$ & 0 & 0 & $(-)$ \\
Total White Blood Cell & - & - & - & $(+)$ \\
Polymorphonuclear Cell & $(-)$ & $(-)$ & $(-)$ & + \\
Mononuclear Cell & $(-)$ & $(-)$ & $(-)$ & $(+)$ \\
\hline
\end{tabular}

As compared to basal levels (recordings): + indicates a significant increase, - indicates a significant decrease and 0 indicates no change. Parenthesis indicates that the changes are not significant but have a tendency to change.

jection as seen in previous studies in ruminants (Fredriksson 1984, Aiumlamai et al. 1990). Total white blood cells decreased significantly from $80 \mathrm{~min}$ to $10 \mathrm{~h}$ post-injection, followed by a tendency of leukocytosis after $36 \mathrm{~h}$. Polymorphonuclear and mononuclear cell counts were also dramatically decreased but the decreases were not significant. The levels then increased and showed cytosis, especially the polymorphonuclear cells which were significantly increased from 36 to $44 \mathrm{~h}$ post-injection. Serum levels of $\mathrm{Ca}$ and $\mathrm{Zn}$ decreased significantly from 2 to 50 $\mathrm{h}$ and 5 to $42 \mathrm{~h}$, respectively, post-injection. The Fe levels showed first an increase and then decrease but these changes were not significant because the variation among animals was high. Levels of GLDH increased significantly from about 40 to $60 \mathrm{~min}$ and persisted for 4 to $20 \mathrm{~h}$ post-injection indicating a severe damage of the liver cells. Bile acids showed a significant increase of the levels from 20 to $40 \mathrm{~min}$ post-injection followed by a tendency to decrease to levels lower than in the control period. Similar findings have been found in the goat (Aiumlamai et al. 1990). No significant changes in $\mathrm{Na}$ and $\mathrm{K}$ concentrations were found, though they had a tendency to increase immediately after injection and to decrease later on.

Figure 1. Effect of intravenous administration of $S$. typhimurium endotoxin $(1.0 \mu \mathrm{g} / \mathrm{kg})$ in 4 heifers presented as mean values. Panel A shows rectal body temperature (BT); B shows peripheral plasma levels of 15-ketodihydro-PGF $2 \alpha$ (PG); C shows total white blood cell (WBC); D shows polymorphonuclear cells (PMN); E shows mononuclear cell (MN); and panels F, G, H, I, J, K and L show sodium ( $\mathrm{Na}$ ), calcium (Ca), zinc $(\mathrm{Zn})$, iron $(\mathrm{Fe})$, glutamate dehydrogenase $(\mathrm{GLDH})$, bile acids (BA) and potassium $(\mathrm{K})$, respectively. 0 indicates time of injection. ${ }^{*}$ indicates that mean values are significantly different $(p<0.05)$ as compared with the control period. 
The high variation in some of the parameters both within and between the animals made it difficult to judge the significances of some of the recorded changes. However, the findings in this study support other papers on the effects of bacterial endotoxins on clinical and blood chemical compositions (eg. Lohuis et al. 1988). Table 1 summarizes the pathophysiological changes seen in the different periods of endotoxaemia in the ruminant.

Suneerat Aiumlamai and Hans Kindahl, Departments of Obstetrics and Gynaecology \& Clinical Chemistry, Swedish University of Agricultural Sciences, S-750 07 Uppsala, Sweden.

\section{References}

Aiumlamai $S$, Fredriksson $G$, Kindahl $H, E d$ qvist LE, Kulander L, Eriksson Ö: Endotoxin concentrations in the blood following intravenous injection and effect on prostaglandin $F_{2 \alpha}$ release, calcium and bile acids in goats. Res. Vet. Sci. 1990, 48, 190-195.

Fredriksson G: Some reproductive and clinical aspects of endotoxins in cows with special emphasis on the role of prostaglandins. Acta vet. scand. 1984, 25, 365-377.

Granström E, Kindahl H: Radioimmunoassay of the major plasma metabolite of $\mathrm{PGF}_{2 a}, 15$ keto-13, 14-dihydro-PGF $2 \alpha$. Methods Enzymol. 1982, 86, 302-339.

Lohuis JACM, Verheijden JHM, Burvenich C, van Miert ASJPAM: Pathophysiological effects of endotoxins in ruminants. Veterinary Quarterly 1988, 10, 109-125.

(Received October 11, 1990; accepted November 19, 1990).

Reprints may be requested from: Suneerat Aiumlamai, Swedish University of Agricultural Sciences, Box 7039, S-75007 Uppsala, Sweden. 